\title{
A METHOD TO PREDICT THE LOAD-DISPLACEMENT RELATIONSHIP OF GROUND ANCHORS
}

\author{
Modèle pour calculer la relation charge-déplacement des ancrages \\ dans les sols
}

\author{
by
}

\section{K. FUJITA}

Dr., Managing Director of Hazama-Gumi, Ltd.

K. UEDA

Deputy Director, Institute of Technology, Hazama-Gumi, Ltd.

M. KUSABUKA

Research Staff, Institute of Technology, Hazama-Gumi, Ltd.

\section{SOMMAIRE}

Des mesures de contrainte effectuées pendant des essais d'ancrage ont montré que la relation entre la contrainte de frottement superficiel du bulbe d'ancrage et le déplacement de celui-ci est non linéaire et que la distribution de la force axiale du bulbe d'ancrage s'étend graduellement vers l'extrémité lorsque la charge augmente.

Afin de donner une explication à ce comportement de l'ancrage dans le sol, nous avons proposé une relation charge-déplacement de l'ancrage en supposant un modèle élastoplastique de relation entre la contrainte de frottement superficiel et le déplacement à un endroit quelconque sur le bulbe d'ancrage. En outre, afin d'appliquer cette formule aux cas réels, nous avons analysé de nombreuses données d'essais d'ancrage et nous avons examiné la relation charge-déplacement, la distribution de la force axiale, et les différentes constantes du sol comprises dans la formule. Nous avons pu ainsi trouver une relation entre les constantes du sol et la valeur $\mathrm{N}$ obtenue lors d'un essai de pénétration standard (S.P.T.).

Par conséquent, si la valeur $\mathrm{N}$ est donnée comme un résultat de reconnaissance du sol, il sera possible de prévoir la relation charge-déplacement de l'ancrage.

\section{SUMMARY}

According to results from measurements of stress obtained by tests of the ground anchor, the relation between skin frictional stress of the anchorage bulb and its displacement is non-linear, and the axial force distribution range of the anchorage bulb expands gradually towards the tip due to increase of the load.

In order to explain such behavior of the ground anchor, we have proposed a formula, which gives the load-displacement relationship of the ground anchor, by assuming an elasto-plastic model of skin frictional stress-displacement relation at a point on the anchorage bulb. Moreover, in order to apply this formula to actual cases, we have ana. lysed numerous data from anchor tests conducted on the site and we have examined the load-displacement relationship, the distribution of axial force. and various ground constants included in the formula. As a result, we have found out a mutual relationship between the ground contants and the $\mathrm{N}$ value of the standard penetration test.

Therefore, if $\mathrm{N}$ value is given as result of the soil investigation, it will be possible to predict the load-displacement relationship of the ground anchor.

\section{INTRODUCTION}

Accurate prediction of the load-displacement relationship is important for the design and construction of ground anchors in order to ensure the safety and economical efficiency of the structures utilizing the anchors.

Accordingly, in order to put forward a method for predicting this load-displacement relationship, studies were carried out; firstly, to find and formulate an analytical method that could adequately account for the behavior of the anchor; secondly, to find a method of estimating the ground characteristic values used in the formula from ground investigation data; and, thirdly, to confirm that the computed values obtained by means of the above prediction method are accurate enough for practical usage when compared with the measured values.
It is recognized, from considerable measurement data, that, unlike conditions in the conventional design methods hitherto employed, the distribution of anchor resistance against the external force is not uniform throughout the entire anchorage bulb, but that when the load applied to the anchor is light most of the load is conveyed to the top part of the anchorage bulb and is not transmitted efficiently as far as the tip part. In other words, as the load increases, the range of distribution of the axial force in the anchorage bulb spreads gradually from the top part of the anchorage bulb towards the tip part. Therefore, concerning the length of anchorage bulb that effectively functions as a resistance to the pulling force, it is necessary to conclude that there exists a critical length that corresponds to the stiffness of the anchorage bulb itself and the ground characteristics. 


\section{ANALYTIC MODEL AND MATRIX FORMULATION}

As shown in fig. 1, the anchor is divided into a finite number of elements, and the nodal point of each element is supported by elasto-plastic spring of the ground.

The linear stiffness equation of the displacement method usually employed shown by the following equation.

$[\mathrm{D}][\mathrm{K}][\mathrm{D}]^{\mathrm{T}}\{\delta\}=\{\mathrm{P}\}$

where,

[D] [K] [D] ${ }^{\mathrm{T}}$ : stiffness matrix;

$\{\delta\}$ : displacement vector;

$\{\mathrm{P}\}$ : load vector.

The skin frictional stress $\tau$ of the anchorage bulb, taken as proportional to axial displacement $\delta$ raised to the $m$ th power, can be expressed as

$$
\tau=\mathrm{C}_{s} \hat{\sigma}^{m}
$$

where,

$\tau$ : skin frictional stress $\left(\mathrm{kg} / \mathrm{cm}^{2}\right)$;

$\mathrm{C}_{\mathrm{s}}$ : coefficient of skin frictional stress $\left(\mathrm{kg} / \mathrm{cm}^{m+2}\right)$;

$\delta$ : axial displacement of anchor $(\mathrm{cm})$;

$m$ : constant.

The ground reaction $\mathrm{R}_{i}$ along the anchor axis at nodal point $i$ can be written

$$
\mathrm{R}_{i}=-\mathrm{K}_{s i} \tilde{\sigma}^{m}
$$

where,

$\mathrm{R}_{i}$ : ground reaction along anchor axis at nodal point $i(\mathrm{~kg})$;

$\mathrm{K}_{s i}$ : coefficient of elasto-plastic spring $=$ $1 / 2 \mathrm{C}_{s} \mathrm{U}\left(\mathrm{L}_{i-1}+\mathrm{L}_{i}\right)\left(\mathrm{kg} / \mathrm{cm}^{m}\right)$;

$\mathrm{L}_{i}$ : length of anchor element $i(\mathrm{~cm})$;

$\mathrm{U}$ : circumference of anchorage bulb $(\mathrm{cm})$.

Addition of equation (3) to the load vector $\{\mathrm{P}\}$ of equation (1) gives

[D] $[\mathrm{K}][\mathrm{D}]^{\mathrm{T}}\{\delta\}+\left[\mathrm{K}_{s}\right]\left\{\delta^{m}\right\}=\{\mathrm{P}\}$

Equation (4) is the stiffness equation of the analytic model shown in fig. 1 , but constant $m$ has to be determined for actual anchor analysis. Here it is assumed that the following equation of Yamakado \& Muta proposed for the skin frictional stress-displacement relationship for a pile will also hold true for an anchor (fig. 2).

$$
\begin{aligned}
& \delta<d, \tau=\mathrm{C}_{s} \delta^{0.5} \\
& \delta \geq d, \tau=\tau_{\max }=\text { const. }
\end{aligned}
$$

where,

$d$ : displacement at yield point $(\mathrm{cm})$;

$\tau_{\max }:$ maximum skin frictional stress $\left(\mathrm{kg} / \mathrm{cm}^{2}\right)$.

From this assumption, we write equation (4) as follows:

[D] $[\mathrm{K}][\mathrm{D}]^{\mathrm{T}}\{\delta\}+\left[\mathrm{K}_{s}\right]\left\{\delta^{0.5}\right\}=\{\mathrm{P}\}$

Numerical analysis of equation (6), in which a nonlinear term is included in the left hand second term, has already been used generally, and so will not be discussed afresh here.

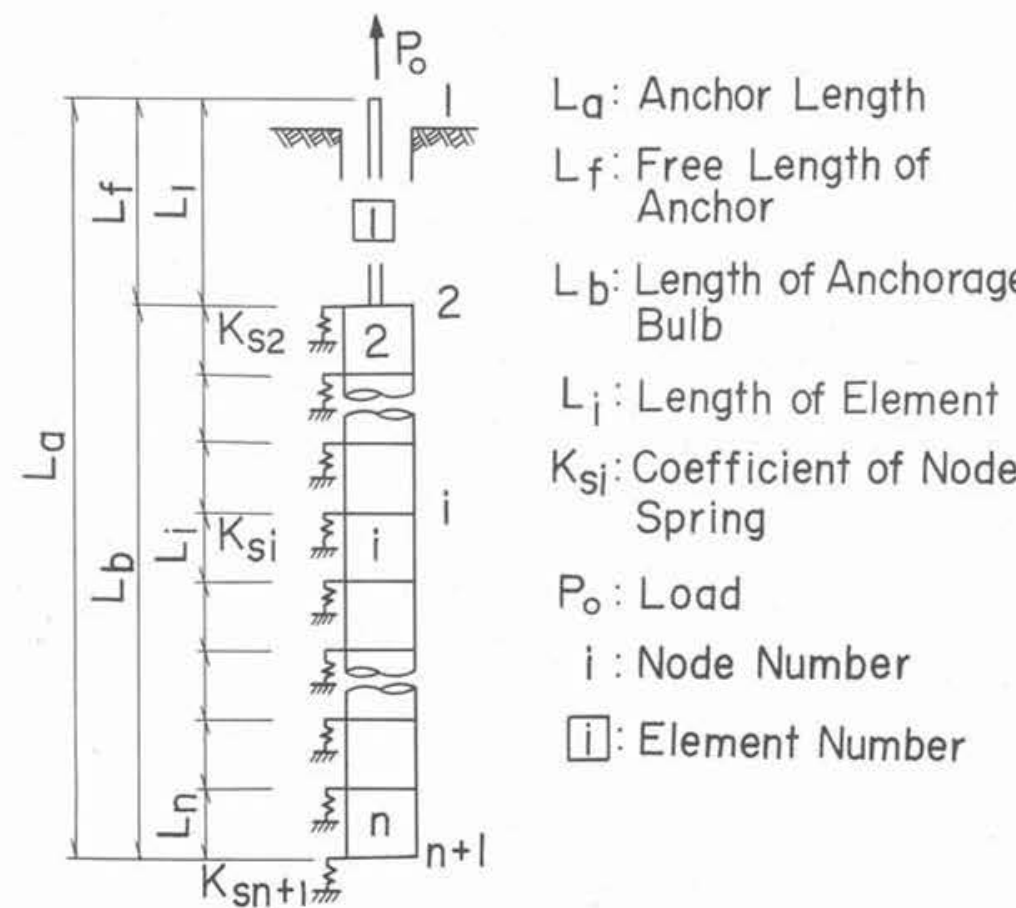

Fig. 1. - Analytical model of anchor.
Fig. 2, - Assumed skin frictional stress $\tau$ : displacement, 5: relationship.

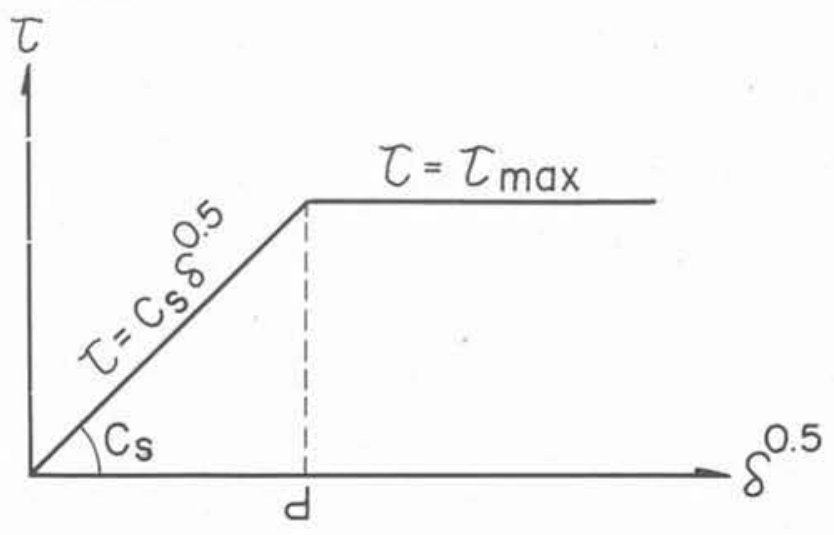


Material characteristics of the anchor can be found by tests conducted on the steel and cement materials used. Usually, however, the actual dimensions of an anchorage bulb constructed in the ground differ from the expected ones, and measurements are impossible without completely extracting or excavating the anchor.

Moreover, measurement of the soil characteristics of the actual ground in which the anchor is being constructed is difficult with the existing measurement techniques.

Accordingly, we propose an indirectly estimating method for coefficient of skin frictional stress of the ground and the effective length of anchorage bulb from the measured load-displacement curve, because ground characteristic values and actual effective anchorage bulb dimensions are great factors for analyzing anchor behavior. by

Measured load-displacement curves are approximated

$$
\mathrm{P}_{0}=\mathrm{K}_{0} \delta_{0}{ }^{n}
$$
where,

$$
\begin{aligned}
& \mathrm{P}_{0} \text { : load; } \\
& \delta_{0}: \text { displacement at anchor head; } \\
& \mathrm{K}_{0} \text { : constant; } \\
& n \text { : constant. }
\end{aligned}
$$

Constants $\mathrm{K}_{0}$ and $n$ of equation (7) are considered as functions of coefficient of skin frictional stress $\mathrm{C}_{s}$, ratio $r$ of anchor length $\mathrm{L}_{a}$ to effective length of anchorage bulb $\mathrm{L}_{b}$, and elastic modulus $\mathrm{E}$ and crosssectional area $\mathrm{A}$ of the anchor material.

If, as stated, $\mathrm{E}$ and $\mathrm{A}$ are considered known quantities, we can consider constants $\mathrm{K}_{o}$ and $n$ as functions only of $\mathrm{C}_{s}$ and $r$, and the following equation becomes applicable.

$$
\begin{aligned}
\mathrm{K}_{o} & =f_{1}\left(\mathrm{C}_{s}, r\right) \\
n & =f_{2}\left(\mathrm{C}_{s}, r\right)
\end{aligned}
$$

where,

$r: \mathrm{L}_{b} / L_{a}(0<r \leq 1)$, which will be termed ratio of effective length;

$\mathrm{L}_{a}$ : anchor length $=\mathrm{L}_{f}+\mathrm{L}_{b}$;

$\mathrm{L}_{f}$ : effective free length of anchor;

$\mathrm{L}_{b}$ : effective length of anchorage bulb.

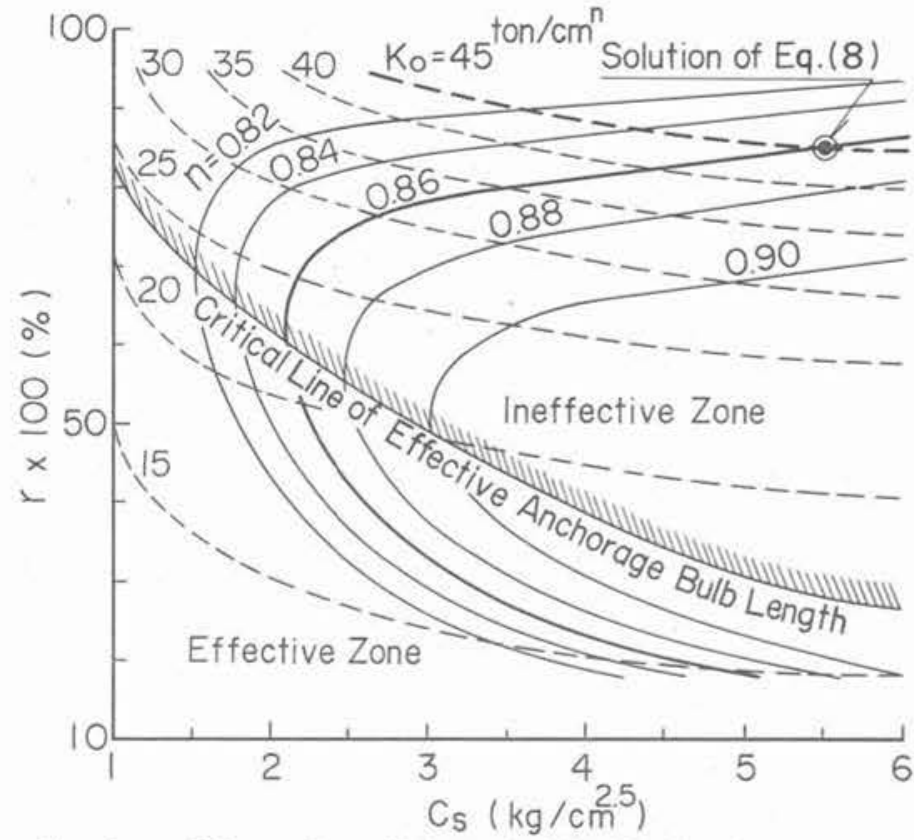

Fig. 3. - Effect of coefficient of skin frictional stress $\mathrm{C}_{\text {s }}$ and ratio of effective length $\mathbf{r}$ on approximate equation of load-displacement curve $\mathbf{P}_{u}=\mathbf{K}_{s} \quad \delta_{u}{ }^{n}$ (test data $\mathbf{N}^{\circ}{ }^{2}$ ).

Equation (8) provides two unknown quantities, $\mathrm{C}_{s}$ and $r$, for a given anchor length $\mathrm{L}_{\alpha}$ and constants $\mathrm{K}_{o}$ and $n$; but as functional forms $f_{1}$ and $f_{2}$ are unclear, it is unclear whether there really exists only one solution that satisfies engineering requirements.

So numerical calculations using equation (6) were carried out to find the effect of variations in unknown quantities, $\mathrm{C}_{s}$ and $r$ on constants $\mathrm{K}_{o}$ and $n$ for an arbitrary anchor model. The results clarified that there exists only one solution for unknown quantities $\mathrm{C}_{s}$ and $r$ that satisfies a given load-displacement curve, that is, the approximation curve equation (7) (for explanation, see fig. 3).

Therefore, if constants $\mathrm{K}_{o}$ and $n$ can be determined by approximation of the measured load-displacement curve using equation (7), it becomes possible, using these values, to estimate coefficient of skin frictional stress $\mathrm{C}_{s}$ and ratio of effective length $r$ as shown in fig. 3 .

\section{GROUND CHARACTERISTIC VALUES}

Ground characteristic values were obtained by analysing the test data of thirty ground anchors according to the above method the tests being carried out at the actual construction site. The ground anchors used for the analyses were all of the cement mortar (or paste) grouted type without reaming.

Fig. 4 and fig. 5 are the results of analyses of coefficient of skin frictional stress $\overline{\mathrm{C}}_{s}$ and displacement at yield point $\bar{d}$ when the subject ground was dealt with as if it was a single-stratum, made to correspond with mean value $\bar{N}$ of the $N$ values of the ground around the anchorage bulb obtained by means of standard penetration tests.
In fig. $6, \overline{\mathrm{C}}_{s}$ of fig. 4 and $\bar{d}$ of fig. 5 are used to calculate by means of equation (5) the maximum frictional stress $\bar{\tau}_{\max }$, which is made to correspond with mean $\mathrm{N}$ value $\overline{\mathrm{N}}$.

Further, the following equation was used to calculate the mean $\mathrm{N}$ value $\overline{\mathrm{N}}$ of multi-stratum ground, and to deal with the ground if it was a single-stratum.

$$
\overline{\mathrm{N}}=\frac{\Sigma a_{i} \mathrm{~N}_{i}}{\mathrm{~L}_{b}}
$$

where,

$\overline{\mathrm{N}}$ : mean $\mathrm{N}$ value for single-stratum ground;

$a_{i}$ : thickness of stratum $i$;

$\mathrm{N}_{i}$ : $\mathrm{N}$ value of stratum $i$. 


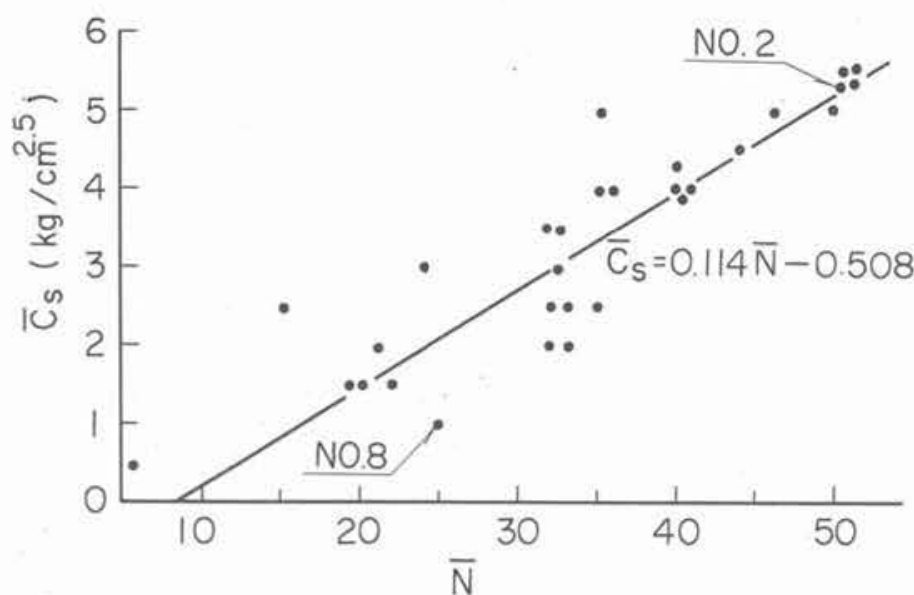

Fig. 4. - Relationship between coefficient of skin frictional stress $\overline{\mathbf{C}}_{i}$ and mean $\mathbf{N}$ value $\overline{\mathbf{N}}$ for single-stratum.

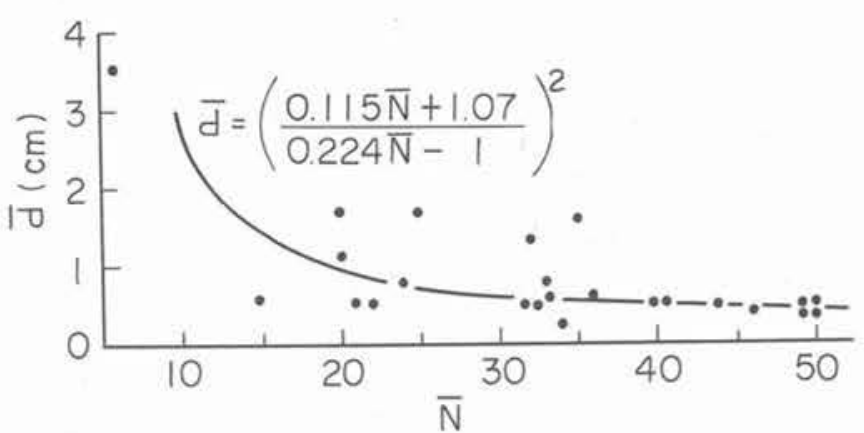

Fig. 5. - Relationship between displacement at yield point $\overline{\mathrm{d}}$ and mean $\mathbf{N}$ value $\overline{\mathbf{N}}$ for single-stratum.

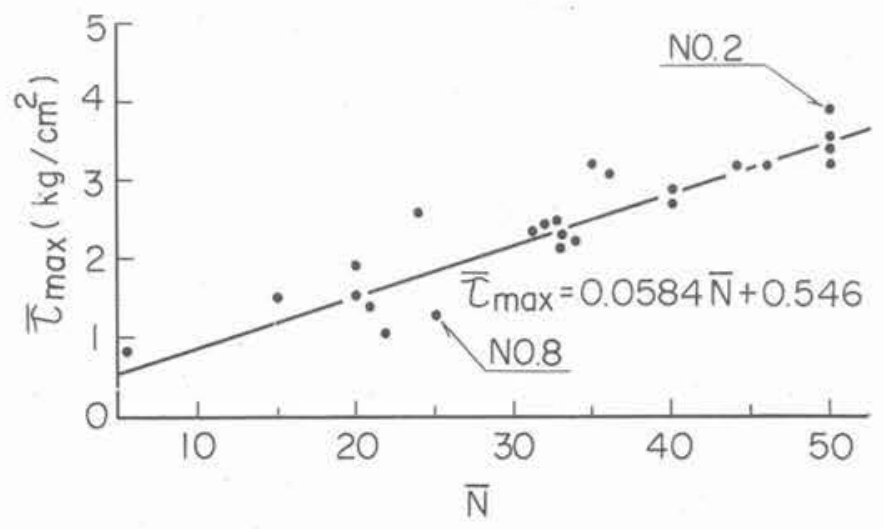

Fig. 6. - Relationship between maximum skin frictional stress $\bar{\tau}_{\max }$ and mean $\mathbf{N}$ value $\overline{\mathbf{N}}$ for single-stratum.

\section{CONCLUSIONS}

The following conclusions were obtained from the results of the above analyses.

(1) By following the method described herein, it is possible to estimate the coefficient of frictional stress $\mathrm{C}_{s}$ and effective anchorage bulb length $\mathrm{L}_{b}$ from the measured load-displacement curve.

(2) In the expedient method for estimating the effective free length of the anchor from the load $\mathrm{P}_{o}$-elastic displacement $\delta_{o e}$ curve obtained by deducting from the measured displacement $\delta_{0}$ the residual plastic displacement $\delta_{o p}$ at zero-load time when the load is removed, the estimate should be according to the slope of the initial linear zone of the load-elastic displacement curve (see fig. 7).

(3) There exists a critical length, for the effective anchorage bulb length of the ground anchor and even if the length is made greater than this, no evident increase in pulling resistance can be expected (see fig. 8).

(4) The coefficient of skin frictional stress $\bar{C}_{\mathrm{s}}$, displacement at yield point $\bar{d}$, and maximum skin frictional stress $\bar{\tau}_{\max }$ for a single stratum can be estimated, using the mean $\mathrm{N}$ value $\overline{\mathrm{N}}$ obtained from equation (9), by means of the following equation.

$$
\begin{array}{ll}
\overline{\mathrm{C}}_{s} & =0.114 \overline{\mathrm{N}}-0.508 \\
\bar{\tau}_{\max } & =0.0584 \overline{\mathrm{N}}+0.546 \\
\bar{d} & =\left(\bar{\tau}_{\max } / \overline{\mathrm{C}}_{s}\right)^{2}
\end{array}
$$

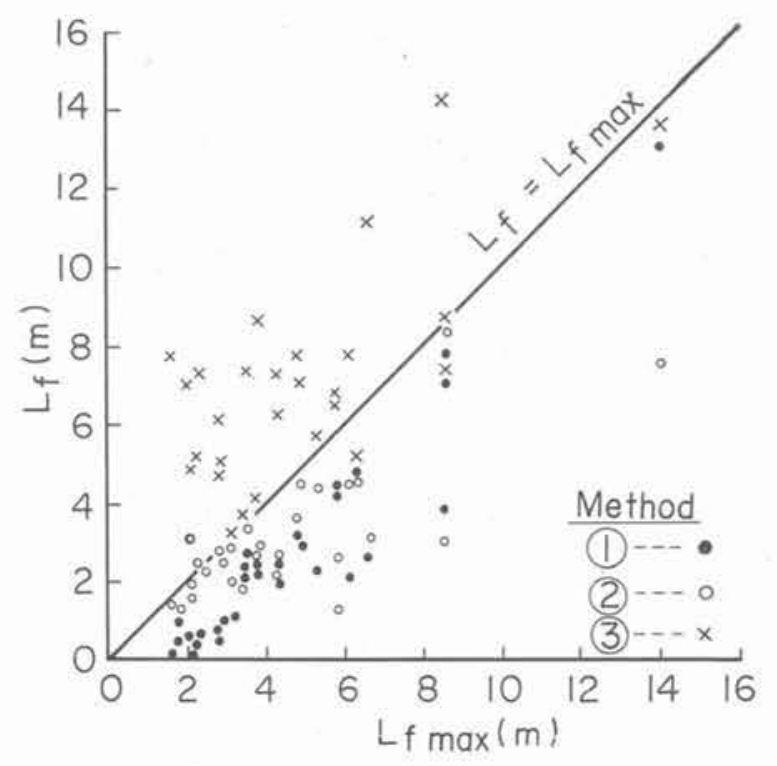

Fig. 7. - Comparison of free length of anchor $\mathbf{l}_{f}$ estimated by three methods.

$\mathbf{L}_{f \max }: \mathbf{E A}\left[\bar{\delta}_{o} / \mathbf{P}_{o}\right]$ initial.

$\mathbf{L}_{f}$ : Method 1, estimation method shown in this paper. Method 2, EA $\left[\delta_{o e} / \mathbf{P}_{o}\right]$ initial.

Method 3, EA $\left[\hat{o}_{o e} / \mathbf{P}_{o}\right]$ latter. 


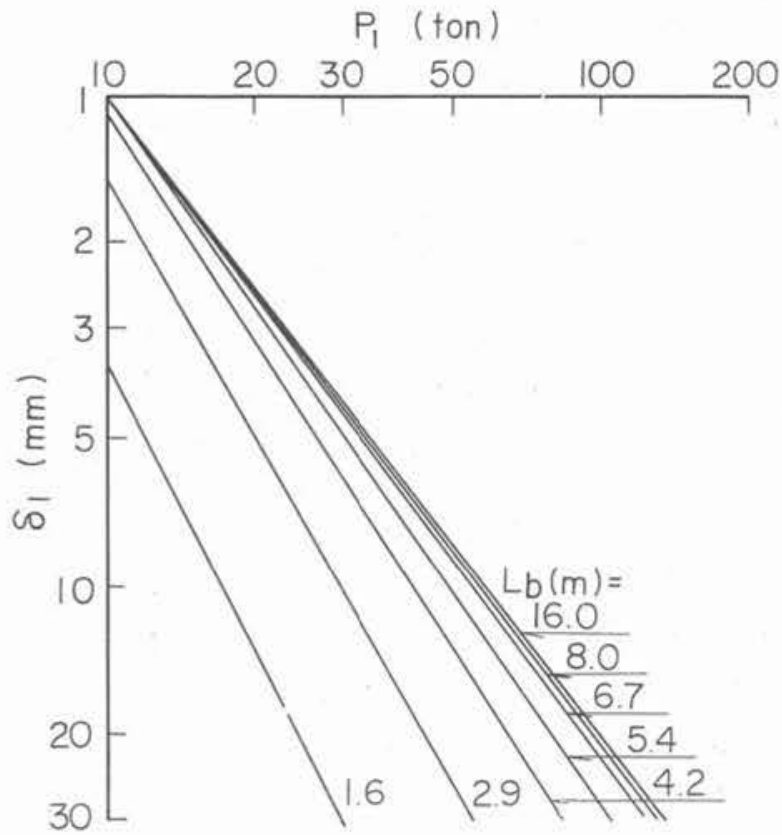

Fig. 8. - Effect of anchorage bulb length $\mathbf{L}_{b}$ on the load $\mathbf{P}_{1}$-displacement $\delta_{1}$ relationship at anchorage bulb top (test data $\mathrm{N}^{\circ} 2$ ).

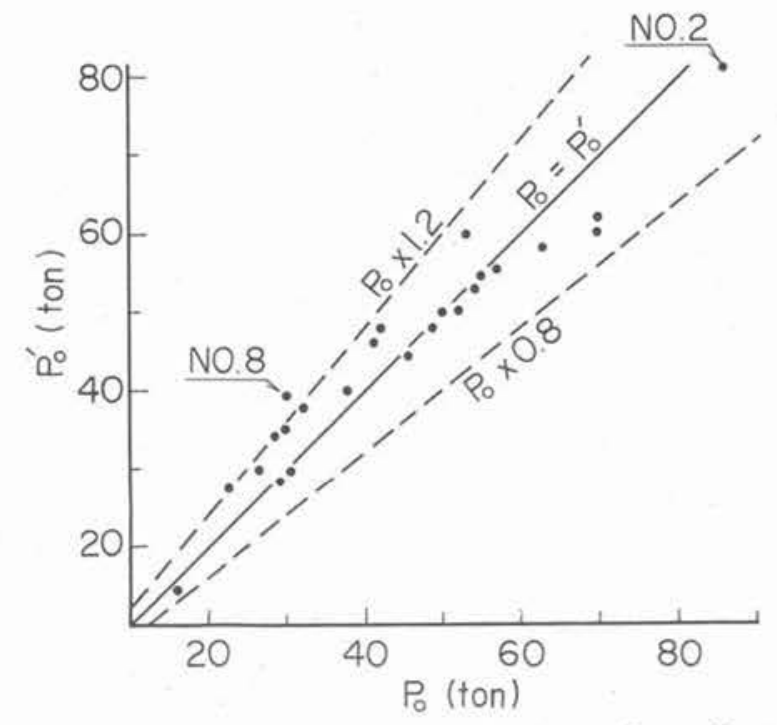

Fig, 9, - Comparison of measured load $\mathbf{P}_{0}$ with predicated load $\mathrm{P}^{\prime}$ 。 at yield point of load-displacement curve plotted on log-log scale.

Fig, 10. - Comparison of analytical result of the load $P_{0}$ - displacement $\delta_{0}$ curve with measured values.

a) Good example, test data $\mathrm{N}^{\circ} 2$.

b) Poor example, test data $\mathrm{N}^{\circ} 8$.

a)

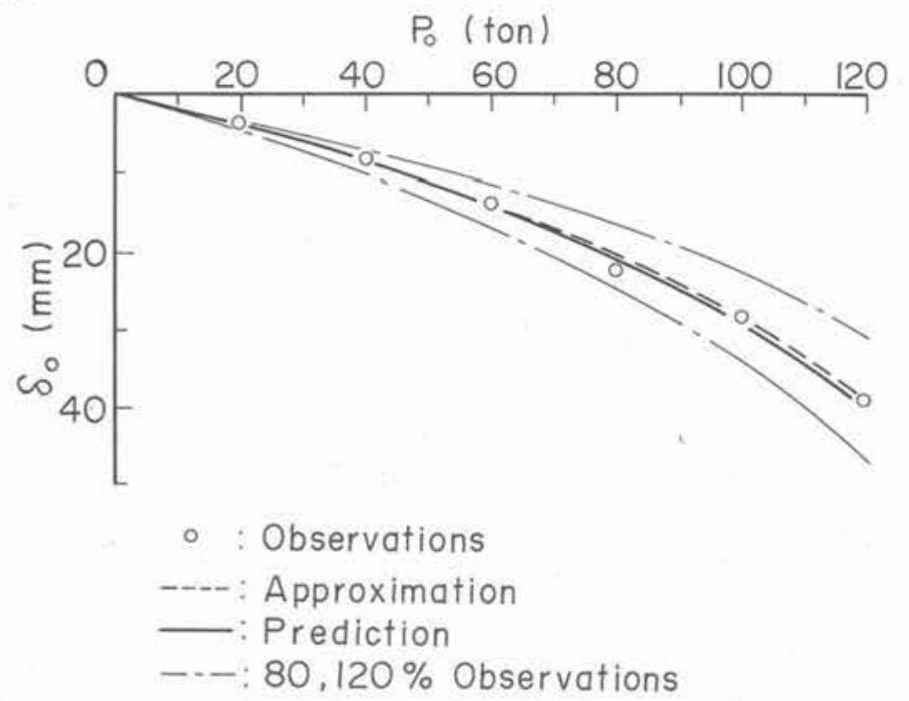

b)

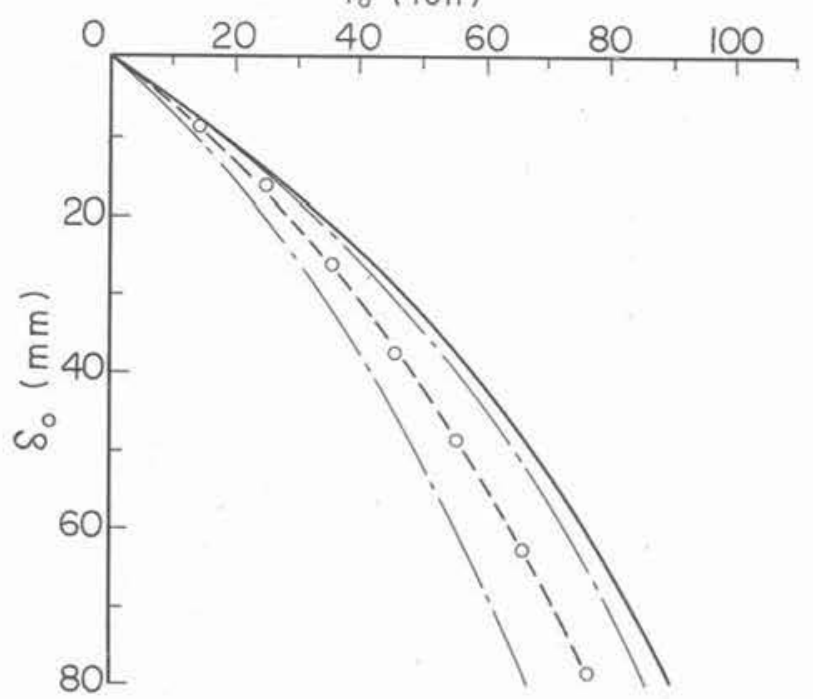

(5) By use of the ground constants calculated by means of equation (10), the load-displacement relationship calculated with equation (6) is sufficiently accurate for practical application (see fig. 9 and fig. 10).

\section{AFTERWORD}

It has been definitely shown by the above that this method of analysis is capable of fully describing the behavior of a ground anchor, and is an effective method in practice, too.

$\mathrm{N}$ values of standard penetration tests in ground investigation data accompanying existing anchor test data were used for estimations of the ground charac- teristic values required for actual application of this method. However, it is considered insufficient to use $\mathrm{N}$ values for this, so suitable ground investigation methods need to be developed.

Considerable information was gained in the course of this research but this will be presented in other papers.

\section{REFERENCE}

YAMAKADO (A.), OHCHI (Y.) and MUTA (C.), Nonlinear Analysis of Pile by Matrix Method,
Proc. Annual Meeting of ISCE (29th), Part III, pp. 218-219 (in Japanese) (1973). 